\title{
Nicotinic $\alpha 7$ receptor activation selectively potentiates the function of NMDA receptors in glutamatergic terminals of the nucleus accumbens
}

\author{
Stefania Zappettini ${ }^{1+}$, Massimo Grilli ${ }^{2}$, Guendalina Olivero ${ }^{2}$, Jiayang Chen ${ }^{2}$, Cristina Padolecchia ${ }^{2}$, \\ Anna Pittaluga ${ }^{2,3}$, Angelo R. Tomée ${ }^{4,5}$, Rodrigo A. Cunha ${ }^{4,6}$ and Mario Marchi ${ }^{2,3}$ * \\ ${ }^{1}$ Faculté de Médecine, Institut de Neurosciences des Systèmes Inserm UMR1106, Aix Marseille Université La Timone, Marseille, France \\ ${ }^{2}$ Department of Pharmacy, University of Genoa, Viale Cembrano, Genoa, Italy \\ ${ }^{3}$ Center of Excellence for Biomedical Research, University of Genoa, Genoa, Italy \\ ${ }^{4}$ CNC-Center for Neuroscience and Cell Biology, University of Coimbra, Coimbra, Portugal \\ ${ }^{5}$ Department of Life Sciences, Faculty of Sciences and Technology, University of Coimbra, Coimbra, Portugal \\ ${ }^{6}$ Faculty of Medicine, University of Coimbra, Coimbra, Portugal
}

\section{Edited by:}

Milos Petrovic, University of

Belgrade, Serbia

\section{Reviewed by:}

Jan Krusek, Czech Academy of Sciences, Czech Republic

Thomas Edward Chater, RIKEN, Japan

${ }^{*}$ Correspondence:

Mario Marchi, Department of Pharmacy, University of Genoa, Viale Cembrano 4, 16148 Genoa, Italy

e-mail:marchi@pharmatox.unige.it

${ }^{\dagger}$ These authors have contributed equally to this work.
We here provide functional and immunocytochemical evidence supporting the co-localization and functional interaction between nicotinic acetylcholine receptors (nAChRs) and N-methyl-D-aspartic acid receptors (NMDARs) in glutamatergic terminals of the nucleus accumbens (NAc). Immunocytochemical studies showed that a significant percentage of NAc terminals were glutamatergic and possessed GluN1 and $\alpha 7$-containing nAChR. A short-term pre-exposure of synaptosomes to nicotine $(30 \mu \mathrm{M})$ or choline (1 $\mathrm{mM}$ ) caused a significant potentiation of the $100 \mu \mathrm{M}$ NMDA-evoked $\left[{ }^{3} \mathrm{H}\right] \mathrm{D}$-aspartate $\left(\left[{ }^{3} \mathrm{H}\right] \mathrm{D}-\mathrm{Asp}\right)$ outflow, which was prevented by $\alpha$-bungarotoxin (100 nM). The pre-exposure to nicotine $(100 \mu \mathrm{M})$ or choline $(1 \mathrm{mM})$ also enhanced the NMDA-induced cytosolic free calcium levels, as measured by FURA-2 fluorescence imaging in individual NAc terminals, an effect also prevented by $\alpha$-bungarotoxin. Pre-exposure to the $\alpha 4$-nAChR agonists 5IA85380 (10 nM) or RJR2429 (1 $\mu \mathrm{M})$ did not modify NMDA-evoked ([ $\left.\left.{ }^{3} \mathrm{H}\right] \mathrm{D}-\mathrm{Asp}\right)$ outflow and calcium transients. The NMDA-evoked ([ $\left.\left.{ }^{3} \mathrm{H}\right] \mathrm{D}-\mathrm{Asp}\right)$ overflow was partially antagonized by the NMDAR antagonists MK801, D-AP5, 5,7-DCKA and R(-)CPP and unaffected by the GluN2B-NMDAR antagonists Ro256981 and ifenprodil. Notably, pre-treatment with choline increased GluN2A biotin-tagged proteins. In conclusion, our results show that the GluN2A-NMDA receptor function can be positively regulated in NAc terminals in response to a brief incubation with $\alpha 7$ but not $\alpha 4$ nAChRs agonists. This might be a general feature in different brain areas since a similar nAChR-mediated bolstering of NMDA-induced ([ $\left.\left.{ }^{3} \mathrm{H}\right] \mathrm{D}-\mathrm{Asp}\right)$ overflow was also observed in hippocampal synaptosomes.

Keywords: nicotinic receptors, NMDA receptors, nicotine treatment, neurotransmitters release, synaptosomes, nucleus accumbens

\section{INTRODUCTION}

Adaptive changes in the glutamatergic inputs triggering information processing in the nucleus accumbens (NAc) are increasingly recognized as key features underlying mood dysfunction and addiction (Carlezon and Thomas, 2009; Reissner and Kalivas, 2010). In particular N-methyl-D-aspartic acid receptors (NMDARs) play a critical role in these adaptive changes (Ma et al., 2009), which are modulated by the cholinergic system, namely through nicotinic acetylcholine receptors (nAChRs; Giocomo and Hasselmo, 2007; Timofeeva and Levin, 2011). These two signaling systems are intertwined as heralded by the ability of nicotine to modulate both the subunit composition (Delibas et al., 2005; Levin et al., 2005; Wang et al., 2007) and several functions of NMDAR (Yamazaki et al., 2006; Liechti and Markou, 2008; Lin et al., 2010; Li et al., 2013; Ávila-Ruiz et al., 2014; Callahan et al., 2014; Salamone et al., 2014). This interaction between nAChR and NMDAR seems most evident 
in nerve terminals (Lin et al., 2010; Salamone et al., 2014): this is of particular interest in view of the increasingly recognized role of presynaptic NMDARs in the control of synaptic plastic changes in different brain areas (Sjöström et al., 2003; Corlew et al., 2008; Bidoret et al., 2009). Thus, we now combined immunological, pharmacological and neurochemical approaches applied to purified nerve terminals to study NMDAR function in glutamatergic terminals in the NAc and we tested whether these presynaptic NMDARs were controlled by nAChRs.

\section{MATERIALS AND METHODS}

\section{ANIMALS AND BRAIN TISSUE PREPARATION}

Adult male rats (Sprague-Dawley, 200-250 g) were housed at constant temperature $\left(22 \pm 1^{\circ} \mathrm{C}\right)$ and relative humidity $(50 \%)$ under a regular light-dark schedule (light 7.00 a.m.-7.00 p.m.) with food and water freely available. The experimental procedures were approved by the Ethical Committee of the Pharmacology and Toxicology Section (University of Genoa) (protocol number 124/2003-A), in accordance with the Italian and European legislation on animal experimentation (2010/63/EU). All efforts were made to minimize animal suffering and to use the minimal number of animals required to produce reliable results.

\section{PREPARATION OF SYNAPTOSOMES}

Synaptosomes were prepared essentially as previously described (Grilli et al., 2008, 2009). Rats were killed by decapitation, their brains were rapidly removed at $0-4^{\circ} \mathrm{C}$ and dissected to collect the NAc (sections between Bregma 0.7-2.2 mm), according to the atlas of Paxinos and Watson (1986), or the hippocampus. The tissue was homogenized in 40 volumes of $0.32 \mathrm{M}$ sucrose, buffered to $\mathrm{pH} 7.4$ with phosphate (final concentration 0.01 $\mathrm{M})$. The homogenate was centrifuged at $1000 \mathrm{~g}$ for $5 \mathrm{~min}$, to remove nuclei and cellular debris, and crude synaptosomes were isolated from the supernatant by centrifugation at $12,000 \mathrm{~g}$ for $20 \mathrm{~min}$. The synaptosomal pellet was then resuspended in Krebs medium with the following composition $(\mathrm{mM}): \mathrm{NaCl} \mathrm{128,} \mathrm{KCl}$ 2.4, $\mathrm{CaCl}_{2}$ 3.2, $\mathrm{KH}_{2} \mathrm{PO}_{4}$ 1.2, $\mathrm{MgSO}_{4}$ 1.2, HEPES 25, glucose 10, $\mathrm{pH}$ 7.2-7.4. The purification of nerve terminals for calcium imaging and immunocytochemical assays was carried out using a sucrose/Percoll fractionation, as previously described (Rodrigues et al., 2005).

\section{NEUROTRANSMITTER RELEASE}

The release of glutamate was gauged using the non-metabolizable tracer $\left[{ }^{3} \mathrm{H}\right] \mathrm{D}$-aspartate $\left(\left[{ }^{3} \mathrm{H}\right] \mathrm{D}\right.$-Asp $)$, which was loaded by incubation of the synaptosomes for $20 \mathrm{~min}$ at $37^{\circ} \mathrm{C}$ with $0.08 \mu \mathrm{M}$ $\left[{ }^{3} \mathrm{H}\right] \mathrm{D}$-Asp. Identical samples of the synaptosomal suspension were then layered over microporous filters at the bottom of parallel superfusion chambers thermostated at $37^{\circ} \mathrm{C}$ and the synaptosomes were superfused with a flow rate of $0.5 \mathrm{~mL} / \mathrm{min}$ with Krebs medium. After $36 \mathrm{~min}(t=36 \mathrm{~min})$, four consecutive 3 -min fractions of the eluent were collected. Synaptosomes were then exposed to NMDAR agonists $(100 \mu \mathrm{M}$ NMDA and $10 \mu \mathrm{M}$ glycine) or to depolarizing agent (4-aminopyridine, 4AP, $10 \mu \mathrm{M}$ ) from $t=39$ min onwards, while antagonists were present from 8 min before addition of the agonists onwards. Exposure to nAChR agonists was done at $t=29 \mathrm{~min}$ for $10 \mathrm{~min}$ in absence or in presence of nAChR antagonists. The superfusate samples and the synaptosomes were then counted for radioactivity. Agonist effects were expressed as percent of the induced outflow over basal outflow, upon subtraction of the radioactivity released in the four fractions collected under basal condition (no drug added) from that released in presence of the stimulus.

\section{CALCIUM IMAGING}

Purified nerve terminals (500 $\mu \mathrm{g}$ of protein) were resuspended in $1 \mathrm{~mL}$ of HEPES-buffered medium (HBM with $122 \mathrm{mM} \mathrm{NaCl}$, $3.1 \mathrm{mM} \mathrm{KCl}, 0.4 \mathrm{mM} \mathrm{KH} 2 \mathrm{PO} 4,5 \mathrm{mM} \mathrm{NaHCO} 3,1.2 \mathrm{mM} \mathrm{MgSO}_{4}$, $10 \mathrm{mM}$ HEPES, $10 \mathrm{mM}$ glucose, $\mathrm{pH}$ 7.4). They were loaded with FURA-2 through incubation with HBM supplemented with $5 \mu$ M FURA-2-AM, $0.02 \%$ pluronic acid F-127, 0.1\% bovine serum albumin (BSA, fatty-acid free) and $1.33 \mathrm{mM} \mathrm{CaCl}_{2}$ for $1 \mathrm{~h}$ at $25^{\circ} \mathrm{C}$ and then allowed to attach onto poly-D-lysine-coated coverslips. The terminals were washed with HBM containing $1.33 \mathrm{mM} \mathrm{CaCl}_{2}$ and mounted in a small superfusion chamber (RC-20; Warner Instruments, Harvard, UK) on the stage of an inverted fluorescence microscope (Axiovert 200; Carl Zeiss, Jena, Germany).

Nerve terminals were alternately excited with UV light centered at 340 and $380 \mathrm{~nm}$ using an optical splitter (Lambda DG4; Sutter Instruments, Novato, CA, USA), with an exposure time of $2360 \mathrm{~ms}$, and the emitted fluorescence images were captured through a $40 \times$ oil objective and a $510 \mathrm{~nm}$ band-pass filter (Carl Zeiss) connected to a digital camera (Cool SNAP; Roper Scientific, Trenton, NJ, USA). Results were expressed by plotting the time course of the ratio, $R$, of the average fluorescence light intensity emitted by a small elliptical region inside each terminal upon alternated excitation at 340 and $380 \mathrm{~nm}(R=\mathrm{F} 340 / \mathrm{F} 380)$.

Increases in $\mathrm{R}$ correspond to increases of the levels of cytosolic free calcium, $\left[\mathrm{Ca}^{2+}\right.$ ] (Lev-Ram et al., 1992; Castro et al., 1995). The basal ratio was measured during $60 \mathrm{~s}$ (i.e., 12 cycles) before stimulating the nerve terminals by superfusion with NMDA (100 $\mu \mathrm{M})+$ glycine $(10 \mu \mathrm{M})$ for $60 \mathrm{~s}$. To measure the effects of the pretreatment with different agonists and antagonists, nicotine (100 $\mu \mathrm{M})$, 5IA85380 (10 $\mathrm{nM})$, choline $(1 \mathrm{mM})$ and $\alpha$-bungarotoxin $(10 \mathrm{nM})$ were added $1 \mathrm{~min}$ before the stimulus. A $30 \mathrm{~s}$ pulse of $\mathrm{KCl}$ (25 mM) was applied at the end of each experiment to confirm the viability of the studied nerve terminals. Changes in Calcium response were measured as $\Delta \mathrm{R}$, subtracting the baseline (before the drug stimulation) to the peak (after the drug stimulation). All tested compounds were prepared in HBM medium lacking $\mathrm{Mg}^{2+}$ ions to disclose the NMDA receptor-mediated effect, and they were added to the superfused nerve terminals, through a pressurized fast-exchange solution delivery system (AutoMate Scientific, Berkeley, CA, USA), with constant gassing of all superfusion solution with $95 \% \mathrm{O}_{2} / 5 \% \mathrm{CO}_{2}$.

\section{IMMUNOCYTOCHEMICAL ASSAYS}

Nerve terminals (500 $\mu \mathrm{g}$ of protein) were resuspended in $1 \mathrm{~mL}$ of phosphate-buffered saline (PBS, composed of $137 \mathrm{mM} \mathrm{NaCl}$, $2.6 \mathrm{mM} \mathrm{KCl}, 1.5 \mathrm{mM} \mathrm{KH} \mathrm{PO}_{4}, 8.1 \mathrm{mM} \mathrm{Na} \mathrm{HPO}_{4}, \mathrm{pH} 7.4$ ) and allowed to attach onto poly-D-lysine-coated coverslips. The follow-up immuno-characterization of the nerve terminals used in FURA-2 fluorescence imaging experiments required the use 
of grid-etched glass coverslips. The platted nerve terminals were fixed with $4 \%(\mathrm{w} / \mathrm{v})$ paraformaldehyde for $15 \mathrm{~min}$, washed twice with PBS, permeabilized in PBS with $0.2 \%$ Triton X-100 for $10 \mathrm{~min}$, and then blocked for $1 \mathrm{~h}$ in PBS with $3 \%$ BSA and $5 \%$ normal horse serum and washed twice with PBS. Triplicate coverslips from each sample were incubated at $25^{\circ} \mathrm{C}$ for $1 \mathrm{~h}$ and the primary antibodies were diluted in PBS with 3\% BSA and 5\% normal horse serum: mouse anti-GluN1 (1:500), guinea pig anti-vGLUT (1:1000), rabbit anti- $\alpha 7$ nAChR (1:500), rabbit anti- $\alpha 4 \mathrm{nAChR}$ (1:500). After three washes with PBS containing $3 \%$ BSA and 3\% normal horse serum, the nerve terminals were incubated for $1 \mathrm{~h}$ at room temperature with AlexaFluor-594 (red)labeled goat anti-rat IgG secondary antibodies (1:200) together with Alexa Fluor-488 (green)-labeled donkey anti-rabbit and with Alexa Fluor-350 (blue)-labeled donkey anti-mouse IgG secondary antibodies (1:200). We confirmed that the secondary antibodies only yielded a signal in the presence of the adequate primary antibodies and that the individual signals obtained in doublelabeled fields were not enhanced over the signals obtained under single-labeling conditions. After washing and mounting onto slides with Prolong Antifade, the preparations were visualized in a Zeiss Axiovert 200 inverted fluorescence microscope equipped with a cooled CCD camera and analyzed with AxioVision software (version 4.6). Each coverslip was analyzed by counting three different fields containing a minimum of 500 elements each.

\section{BIOTINYLATION AND IMMUNOBLOTTING}

Synaptosomes from the NAc of two rats were re-suspended in $\mathrm{HBM}$ at $4^{\circ} \mathrm{C}$. The cell surface density of GluN2A was evaluated by performing surface biotinylation followed by immunoblots analysis, as previously described (Ciruela et al., 2006), with minimal modications. The synaptosomes were divided into two aliquots (500 $\mu \mathrm{g}$ protein each) and both were incubated for $10 \mathrm{~min}$ at $37^{\circ} \mathrm{C}$ under mild shaking; one aliquot was then treated for 10 min with $1 \mathrm{mM}$ choline (T) while the other was kept as control (C). Choline exposure was terminated by dilution in cold washing buffer composed of $150 \mathrm{mM} \mathrm{NaCl}, 1 \mathrm{mM}$ EDTA, $0.2 \%$ BSA, $20 \mathrm{mM}$ Tris, $\mathrm{pH}$ 8.6. After washing twice in ice-cold washing buffer, the synaptosomes were labeled with $2 \mathrm{mg} / \mathrm{ml}$ of sulfoNHS-SS-biotin in PBS with $1.5 \mathrm{mM} \mathrm{MgCl}_{2}$ and $0.2 \mathrm{mM} \mathrm{CaCl}_{2}$, $\mathrm{pH} 7.4$ (PBS/Ca-Mg) for $1 \mathrm{~h}$ at $4^{\circ} \mathrm{C}$. The biotinylation reaction was stopped by incubating with $1 \mathrm{M} \mathrm{NH}_{4} \mathrm{Cl}$ for $15 \mathrm{~min}$ at $4^{\circ} \mathrm{C}$, followed by two washes with ice cold $100 \mathrm{mM} \mathrm{NH}_{4} \mathrm{Cl}$ in PBS/Ca$\mathrm{Mg}$, to quench biotin. Subsequently, biotinylated synaptosomes were lysed in RIPA buffer $(500 \mu \mathrm{L})$ composed of $150 \mathrm{mM} \mathrm{NaCl}$, $1 \mathrm{mM}$ EDTA, $0.1 \%$ SDS, $1 \%$ Triton X-100, 1\% sodium deoxycholate, $1 \mathrm{mM}$ orthovanadate, protease inhibitor cocktail and $10 \mathrm{mM}$ Tris, $\mathrm{pH}$ 7.4. The lysate was centrifuged at 20,000 $\times g$ for $10 \mathrm{~min}$ at $4^{\circ} \mathrm{C}$, and samples $(100 \mu \mathrm{g})$ were incubated with streptavidin magnetic beads $(40 \mu \mathrm{L})$ for $1 \mathrm{~h}$ at room temperature under shaking. Biotinylated proteins, linked to streptavidin magnetic beads, were then added to pulled-down by exposure of the mixture to a magnetic field. After extensive washes, $1 \times$ SDS-PAGE buffer was added and samples were boiled for 5 min at $95^{\circ} \mathrm{C}$. Proteins were then loaded and electrophoretically separated on a $10 \%$ sodium dodecyl sulfate-PAGE gel and then transferred to PVDF membranes and probed for the proteins of interest by incubation with rabbit anti-GluN2A $(1: 2,000)$ or mouse anti- $\beta$-actin $(1: 10,000)$ primary antibodies for $1 \mathrm{~h}$ at room temperature with Tween 20-containing Tris-buffered saline (t-TBS), composed of $150 \mathrm{mM} \mathrm{NaCl}, 0.1 \%$ Tween $20,5 \%$ non-fat dried milk and $20 \mathrm{mM}$ Tris, $\mathrm{pH}$ 7.4. After washing, membranes were incubated for $1 \mathrm{~h}$ at room temperature with the appropriate horseradish peroxidase-linked secondary antibody (1:20,000), and immunoblots were visualized with an ECL (enhanced chemiluminescence) Plus Western blotting detection system. GluN2A subunit density was determined in the total synaptosomal lysate (Syn) and in the streptavidin-pulled-down fraction of control and choline-pretreated biotinylated synaptosomes (Ctr and Ch, respectively).

\section{DATA ANALYSIS}

Statistical comparison of the results was carried out using a Student's $t$-test for independent means (for single pairs comparison); multiple comparisons were performed with one- or twoway ANOVA followed by Tukey-Kramer post hoc test. Values are expressed as means \pm SEM and are considered significant for $p<0.05$.

\section{MATERIALS}

$\left[2,3-{ }^{3} \mathrm{H}\right] \mathrm{D}$-aspartate (specific activity $11.3 \mathrm{Ci} / \mathrm{mmol}$ ) was from Perkin Elmer (Boston, MA, USA); nicotine hydrogen tartrate salt, 4-aminopyridine (4-AP), N-methyl-D-aspartate (NMDA), fattyacid free BSA, anti- $\beta$-actin monoclonal mouse IgG1, horseradish peroxidase-conjugated anti-mouse and anti-rabbit secondary antibodies and the protease inhibitor cocktail were from SigmaAldrich (St. Louis, MO, USA); 5-iodo-A-85380, ifenprodil, Ro256981, 5,7-dicholoro-kynuremic acid (DCKA), D-AP5, MK801, (R)-CPP and RJR-2403 oxalate were from Tocris (Bristol, UK); FURA-2 AM, pluronic acid F-127 were performed by Molecular Probes, Leiden, Netherlands. $\beta$-actin monoclonal mouse IgG1, horseradish peroxidase-conjugated anti-mouse and anti-rabbit secondary antibodies protease inhibitor cocktail were obtained from Sigma Chemical Co. (St. Louis, MO, USA). Sulfo-NHS-SS-biotin and Streptavidin 14. Magnetic Beads were purchased from Pierce Thermo Scientific (Rockford, IL, USA), Western blotting detection system was purchased from GeHealthcare (Italy). Guinea pig anti-vGLUT, mouse anti-GluN1, AlexaFluor-594 (red)-labeled goat guinea pig IgG, Alexa Fluor488 (green)-labeled donkey anti-rabbit, Alexa Fluor-350 (blue)labeled donkey anti-mouse, secondary antibodies were from Invitrogen. Rabbit anti- $\alpha 4 \mathrm{nAChR}$ (1:500), rabbit anti- $\alpha 7 \mathrm{nAChR}$ and anti-rabbit polyclonal GluN1 antibody was from Chemicon International (Millipore, Billerica, MA, USA).

\section{RESULTS CO-LOCALIZATION AND FUNCTIONAL INTERACTION OF nAChR AND NMDAR IN GLUTAMATERGIC TERMINALS OF THE RAT NUCLEUS ACCUMBENS}

Figure 1 shows that NMDA (100 $\mu \mathrm{M}$, plus $1 \mu \mathrm{M}$ glycine) triggered the release of $\left[{ }^{3} \mathrm{H}\right] \mathrm{D}$-Asp from pre-labeled NAc synaptosomes. A $10 \mathrm{~min}$ pre-exposure of the synaptosomes to nicotine $(100 \mu \mathrm{M})$ or choline $(1 \mathrm{mM})$ significantly potentiated the NMDA-induced $\left[{ }^{3} \mathrm{H}\right] \mathrm{D}$-Asp outflow $(+58 \%$, and 


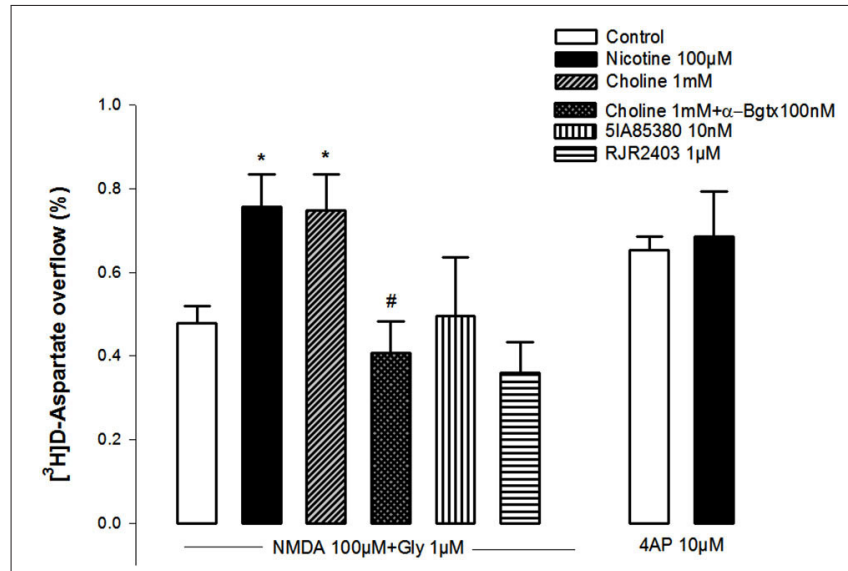

FIGURE 1 | Impact of the pre-treatment during $10 \mathrm{~min}$ with different nAChR agonists on the ability of NMDAR agonists (100 $\mu$ M NMDA and $10 \mu \mathrm{M}$ glycine) and of 4-AP to trigger $\left[{ }^{3} \mathrm{H}\right] \mathrm{D}$-Asp from rat NAc nerve terminals. Data are means \pm SEM of at least five experiments run in triplicate. ${ }^{*} p<0.05$ vs. control; ${ }^{\#} p<0.05$ vs. pretreatment with choline.

$+56 \%$, respectively). This potentiation was abolished in synaptosomes pretreated with the selective $\alpha 7 \mathrm{nAChR}$ antagonist $\alpha$-bungarotoxin (100 $\mathrm{nM}$; Figure 1). In contrast, the preexposure of the synaptosomes to the selective $\alpha 4-\mathrm{nAChR}$ agonist 5IA85380 (10 nM) or RJR2403 (1 $\mu \mathrm{M})$ did not modify the NMDA-induced $\left[{ }^{3} \mathrm{H}\right] \mathrm{D}$-Asp outflow. It should be noted that the pre-treatment of NAc synaptosomes with nicotine failed to modify the 4-AP-induced $\left[{ }^{3} \mathrm{H}\right] \mathrm{D}$-Asp outflow (Figure 1).

The amplitude of the NMDA (100 $\mu \mathrm{M}$, plus $10 \mu \mathrm{M}$ glycine)induced increase in cytosolic free calcium in individual NAc terminals (Figures 2A,B) was also potentiated by preexposure to nicotine (100 $\mu \mathrm{M}$; Figures $2 \mathrm{~A}, \mathbf{B})$ or choline $(1 \mathrm{mM}$; Figures 2C,D), an effect that was blunted by $\alpha$-bungarotoxin (10 nM; Figures 2E,F). These observations provide further evidence that the activation of $\alpha 7$-containing $\mathrm{nAChR}$ bolsters NMDAR-mediated functions in NAc synaptosomes.

We next carried out an immunocytochemical characterization of NAc nerve endings to gauge the extent of the co-localization between $\alpha 7 \mathrm{nAChR}$ and NMDAR in glutamatergic nerve terminals. As shown in Figure 3, we identified individual nerve terminals (e.g., terminal 1) that were glutamatergic (vGluT1positive) and endowed with both GluN1 and $\alpha 7$ subunits (Figures 3B,C), where the pre-treatment with choline $(1 \mathrm{mM})$ potentiated the NMDA $(100 \mu \mathrm{M})$-induced calcium transient (Figure 3A). In fact, this analysis revealed that more than $40 \%$ of glutamatergic nerve terminals (vGluT1-positive) possessed GluN1 and $\alpha 7$ subunits (Figure 3D), thus confirming that the colocalization of NMDAR and $\alpha 7 \mathrm{nAChR}$ on the same glutamatergic terminal is a generalized feature in the NAc. The analysis of individual NAc terminals further revealed non-glutamatergic (vGluT1-negative) NAc terminals (e.g., terminal 2) containing both GluN1 and $\alpha 7$ subunits (Figures 3B,C), where choline (1 $\mathrm{mM})$ failed to modify the NMDA $(100 \mu \mathrm{M})$-induced calcium transient (Figure 3A). We also found terminals that responded

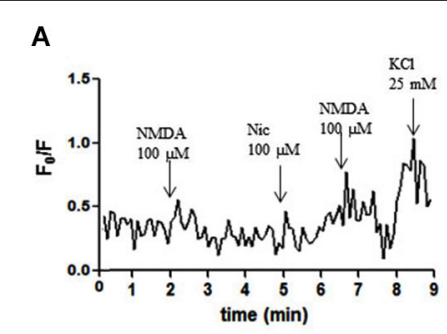

B

C

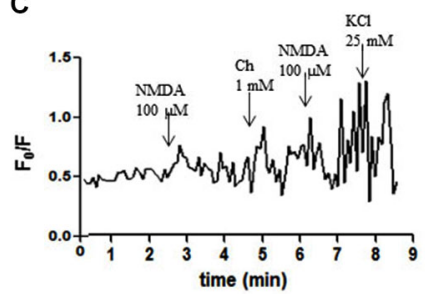

D
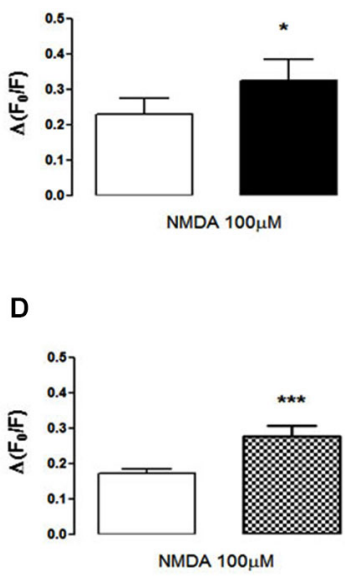

E

$\mathbf{F}$
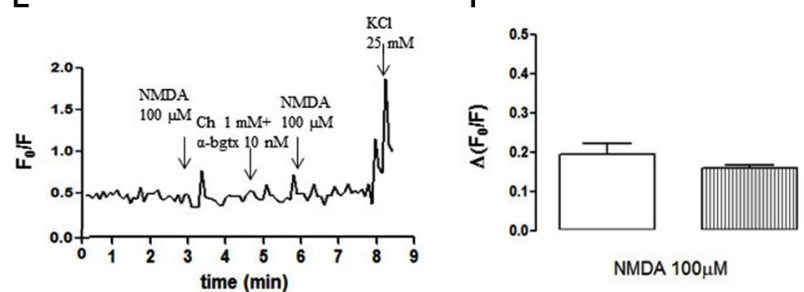

FIGURE 2 | (A, C, E) Time course of FURA-2 fluorescence emission in individual nerve terminals from the rat NAc, which were challenged twice with NMDAR agonists ( $100 \mu \mathrm{M}$ NMDA and $10 \mu \mathrm{M}$ glycine), before and $60 \mathrm{~s}$ after pre-treatment with either $100 \mu \mathrm{M}$ nicotine (A), $1 \mathrm{mM}$ choline (C) or 1 $\mathrm{mM}$ choline together with $10 \mathrm{nM} \alpha$-bungarotoxin (E). (B, D, F) Comparison of the average modification of calcium transients caused by NMDA agonists before (open bars) and $60 \mathrm{~s}$ after (filled bars) the exposure to $100 \mu \mathrm{M}$ nicotine (B), $1 \mathrm{mM}$ choline (D) or $1 \mathrm{mM}$ choline together with $10 \mathrm{nM}$ $\alpha$-bungarotoxin (F). Drugs were applied for $60 \mathrm{~s}$, at the end of the wash out of the previous application and the arrows identify the peaks. Values are mean \pm SEM of at least four experiments ${ }^{*} p<0.05$ and ${ }^{* * *} p<0.001$, using a paired Student's $t$ test.

only to the $\alpha 7 \mathrm{nAChR}$ agonist (e.g., terminal 3 in Figure $3 \mathrm{~A}$ ) or to NMDA (e.g., terminal 4 in Figure 3A).

We also identified individual glutamatergic nerve terminals (vGluT1-positive) containing both GluN1 and $\alpha 4$ subunits (terminal 2; Figures 4B,C), where the pre-treatment with 5IA85380 $(10 \mathrm{nM})$ did not modify the NMDA $(100 \mu \mathrm{M})$-induced calcium transient (Figure 4A). Interestingly, we found other terminals (e.g., terminal 1) also containing both GluN1 and $\alpha 4$ subunits, where the pre-treatment with 5IA85380 (10 nM) actually reduced the NMDA $(100 \mu \mathrm{M})$-induced calcium transients (Figure 4A), a phenomenon previously observed in dopaminergic NAc terminals (Salamone et al., 2014). Additionally, we also observed nerve terminals responding only to NMDA (e.g., terminal 3) or to an $\alpha 4 \mathrm{nAChR}$ agonist (e.g., terminal 4 in Figure 4A). The average co-localization betweenGluN1 and $\alpha 4$ subunits (Figure 4D) showed that only $3-4 \%$ of the NAc glutamatergic nerve endings were endowed with both subunits, in contrast to the frequent co-localization of GluN1 and $\alpha 7$ subunits (Figure 3D). 


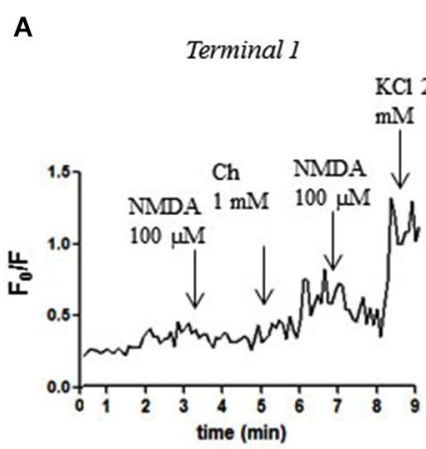

Terminal 2

Terminal 3
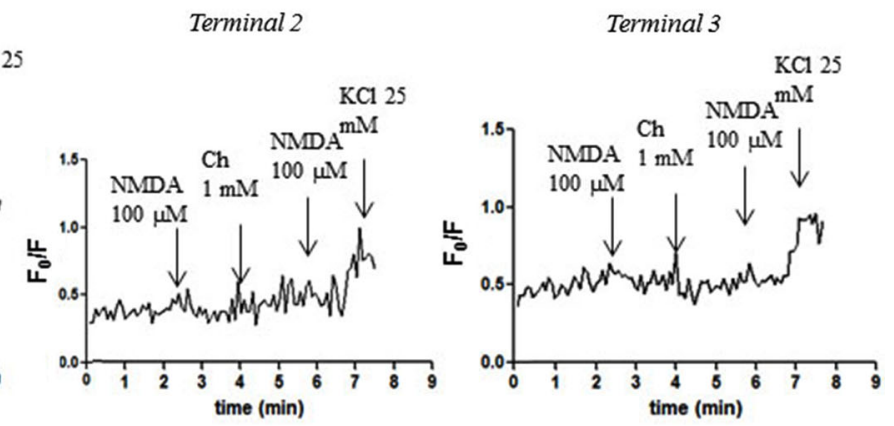

Terminal 4

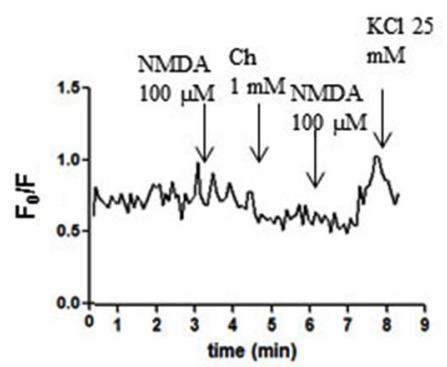

B

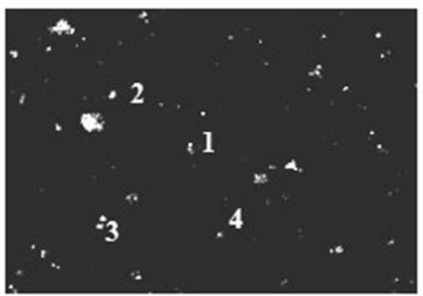

C

D
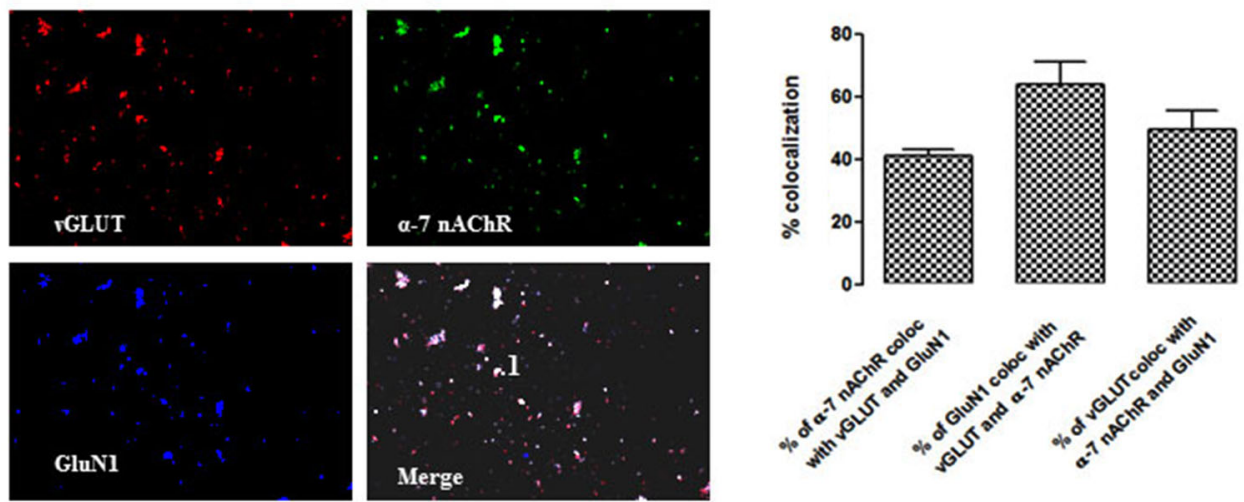

FIGURE 3 | Different impact of choline $(1 \mathrm{mM})$ pre-treatment on the ability of NMDAR agonists to trigger calcium transients in different individual terminals from the rat NAc. (A) Time course of FURA-2 fluorescence emission in different individual nerve terminals (terminal 1-terminal 4), which were challenged twice with NMDAR agonists (100 $\mu \mathrm{M}$ NMDA and $10 \mu \mathrm{M}$ glycine), before and $60 \mathrm{~s}$ after pre-treatment with $1 \mathrm{mM}$ choline. Drugs were applied for $60 \mathrm{~s}$, at the end of the wash out of the previous application and the arrows identify the peaks. (B) Fluorescence image of a field of FURA-2-labelled synaptosomes including terminals 1-4. (C) Immunocytochemical co-localization of $\alpha 7-n A C h R, v G L U T$ and GluN1 in terminal 1. (D) Average co-localization of $\alpha 7-n A C h R, v G L U T$ and GluN1 in nerve terminals from the rat NAc. Values are mean \pm S.E.M of at least four experiments.

\section{PHARMACOLOGICAL CHARACTERIZATION OF NMDAR PRESENT IN NAC GLUTAMATERGIC TERMINALS}

The pharmacological characterization of the NMDAR involved in the NMDA (100 $\mu \mathrm{M})$-evoked $\left[{ }^{3} \mathrm{H}\right] \mathrm{D}$-Asp outflow from NAc synaptosomes is presented in Figure 5. The NMDA (100 $\mu \mathrm{M})$-evoked [ $\left.{ }^{3} \mathrm{H}-\right] \mathrm{D}$-Asp outflow was antagonized by MK801 (10 $\mu \mathrm{M})$ and by D-AP5 $(1 \mu \mathrm{M})$, as well as by the selective GluN1 antagonist 5,7-DCKA (1 $\mu \mathrm{M})$. Furthermore, the GluN2A-preferring antagonist (R)-CPP
(1 $\mu \mathrm{M})$ also attenuated the NMDA (100 $\mu \mathrm{M})$-evoked $\left[{ }^{3} \mathrm{H}\right] \mathrm{D}$-Asp outflow $(-48 \%)$, while the GluN2B-selective antagonists Ro256981 (1 $\mu \mathrm{M})$ and ifenprodil $(1 \mu \mathrm{M})$ were ineffective.

\section{nAChR ACTIVATION DRIVES GIUN2A TRAFFICKING TO THE PLASMA MEMBRANE}

We next tested whether nicotine pre-treatment selectively impacts this NR2A-mediated component of the NMDA-evoked 

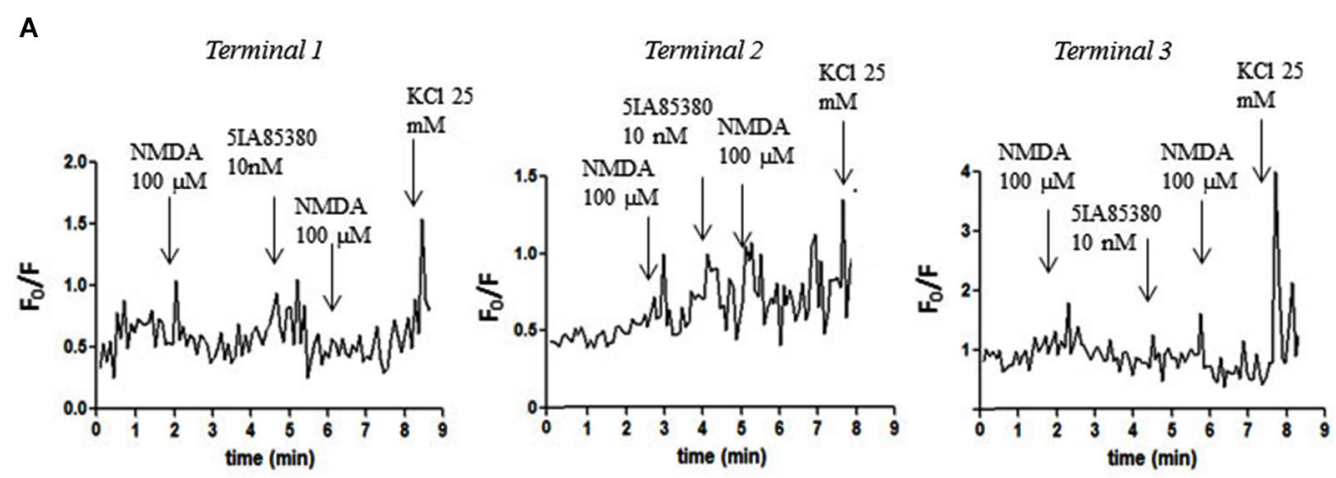

Terminal 4

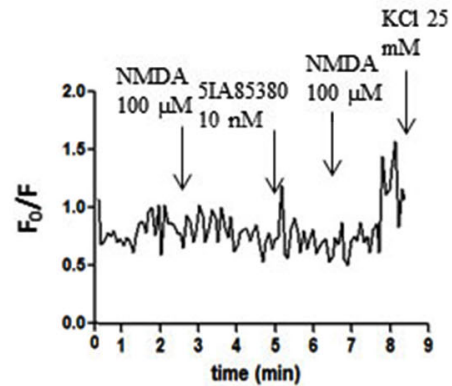

C
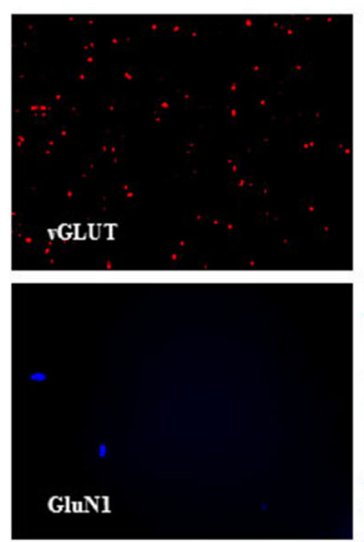
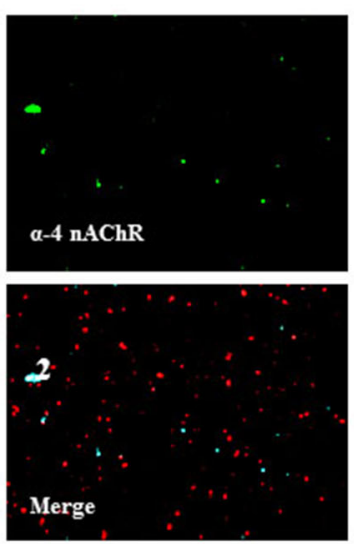

B

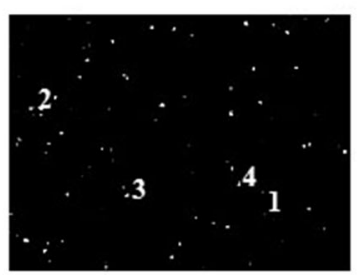

D

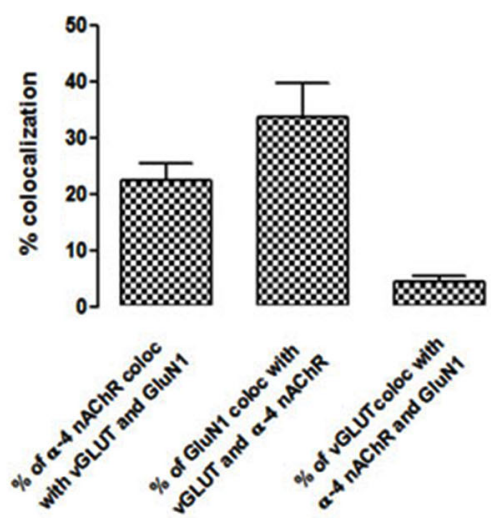

FIGURE 4 | Different impact of 5IA85380 (10 nM) pre-treatment on the ability of NMDAR agonists to trigger calcium transients in different individual terminals from the rat NAc. (A) Time course of FURA-2 fluorescence emission in different individual nerve terminals (terminal 1-terminal 4), which were challenged twice with NMDAR agonists (100 $\mu \mathrm{M}$ NMDA and $10 \mu \mathrm{M}$ glycine), before and $60 \mathrm{~s}$ after pre-treatment with 5IA85380 (10 nM). Drugs were applied for $60 \mathrm{~s}$, at the end of the wash out of the previous application and the arrows identify the peaks. (B) Fluorescence image of a field of FURA-2-labelled synaptosomes including terminals 1-4. (C) Immunocytochemical co-localization of $\alpha 4-n A C h R$, vGLUT and GluN1 in terminal 1. (D) Average co-localization of $\alpha 4-n A C h R$, vGLUT and GluN1 in nerve terminals from the rat NAc. Values are mean \pm S.E.M of at least four experiments. $\left[{ }^{3} \mathrm{H}\right] \mathrm{D}$-Asp outflow. As shown in Figure $\mathbf{6 A}$, after (Choline 1 $\mathrm{mM}$ ) pre-treatment, the inhibitory effect of the NR2A-preferring antagonist (R)-CPP $(1 \mu \mathrm{M})$ was significantly increased $(-78 \%)$ compared to the effects on control (non-pre-treated) synaptosomes ( $-48 \%$; Figure 5). By contrast, nicotine pre-treatment did not enhance the inhibition caused by the NR2B-selective antagonist Ro256981 (1 $\mu \mathrm{M})$, which was still non-significant (Figure 6A).
Since we have previously shown that nAChR can control the responses of presynaptic ionotropic glutamate receptors through the regulation of their trafficking in and out of the plasma membrane (Grilli et al., 2012; Salamone et al., 2014), we posited that the nicotine-induced increase of the NMDA response in NAc glutamatergic terminals would also rely on a control of the trafficking of GluN2A-containing NMDAR. Indeed, the quantification of the density of biotin-tagged 


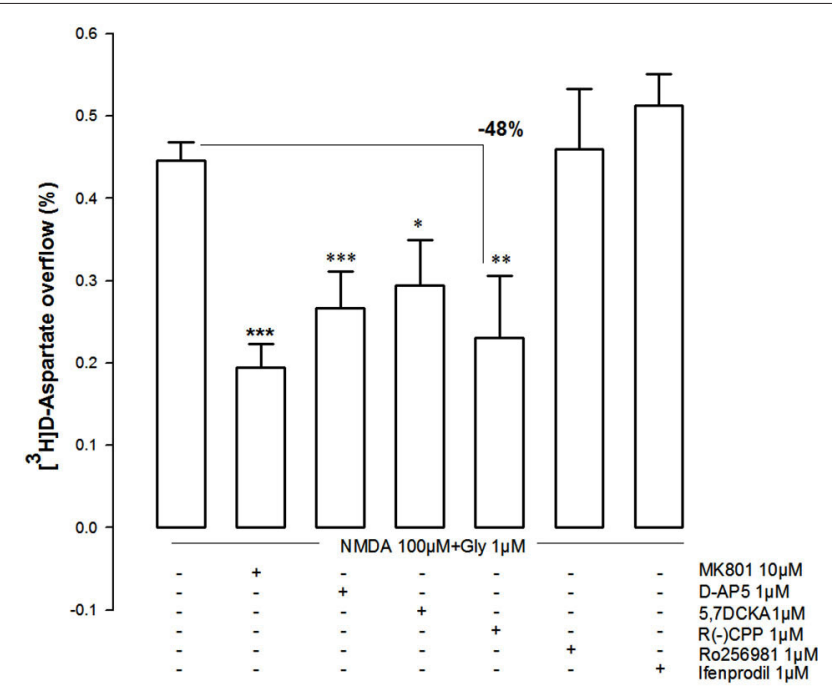

FIGURE 5 | Effect of different NMDAR antagonists on the evoked $\left[{ }^{3} \mathrm{H}\right] \mathrm{D}$-Asp release from rat NAc synaptosomes triggered by $100 \mu \mathrm{M}$ NMDA and $1 \mu \mathrm{M}$ glycine and lack of effect of GluN2B-NMDAR antagonists (Ro256981 and ifenprodil). Data are mean \pm SEM of at least five experiments run in triplicate. ${ }^{*} p<0.05,{ }^{* *} p<0.01,{ }^{* * *} p<0.001$ vs. 100 $\mu \mathrm{M}$ NMDA using a one-way ANOVA followed by Tukey-Kramer post hoc test.

GluN2A subunit proteins in NAc synaptosomes before and after choline pre-treatment (Figures 6B,C) showed that choline
(1 $\mathrm{mM})$ pre-treatment for $10 \mathrm{~min}$ increased $(+15 \%$, Figure $6 \mathrm{C})$ the density of GluN2A at the plasma membrane (Figure 6B, lane $\mathrm{Ch}$ ) respect to control (Figure 6B, lane Ctr).

\section{CHOLINE POTENTIATES THE NMDA-INDUCED D-Asp RELEASE FROM HIPPOCAMPAL NERVE TERMINALS}

$\mathrm{N}$-methyl-D-aspartic acid (100 $\mu \mathrm{M}$, plus $10 \mu \mathrm{M}$ glycine) caused a marked outflow of $\left[{ }^{3} \mathrm{H}\right] \mathrm{D}$-Asp from pre-labeled hippocampal synaptosomes (Figure 7), which was quantitatively higher than that observed in NAc synaptosomes (cf. Figures 1, 7). The preexposure of hippocampal synaptosomes to choline $(1 \mathrm{mM})$ for 10 min significantly potentiated the NMDA-induced $\left[{ }^{3} \mathrm{H}\right] \mathrm{D}$-Asp outflow while the pre-incubation with nicotine $(100 \mu \mathrm{M})$ was ineffective. As observed in NAc synaptosomes, the pre-exposure of hippocampal synaptosomes to the $\alpha 4 \beta 2 \mathrm{nAChR}$ agonists 5IA85380 $(10 \mathrm{nM})$ or cytisine $(100 \mu \mathrm{M})$ for $10 \mathrm{~min}$ did not modify the NMDA-induced $\left[{ }^{3} \mathrm{H}\right] \mathrm{D}$-Asp outflow.

\section{DISCUSSION}

The present study shows that the activation of nAChR enhances the ability of NMDAR to trigger neurotransmitter release from glutamatergic terminals of the NAc. Our combined pharmacological and immunocytochemical characterization at the individual nerve terminal level revealed that this involved the ability of a 7-containing nAChR to selectively bolster GluN2A-containing NMDA receptor function. Further biochemical studies showed that $\mathrm{nAChR}$ activation enhanced the plasma membrane levels of
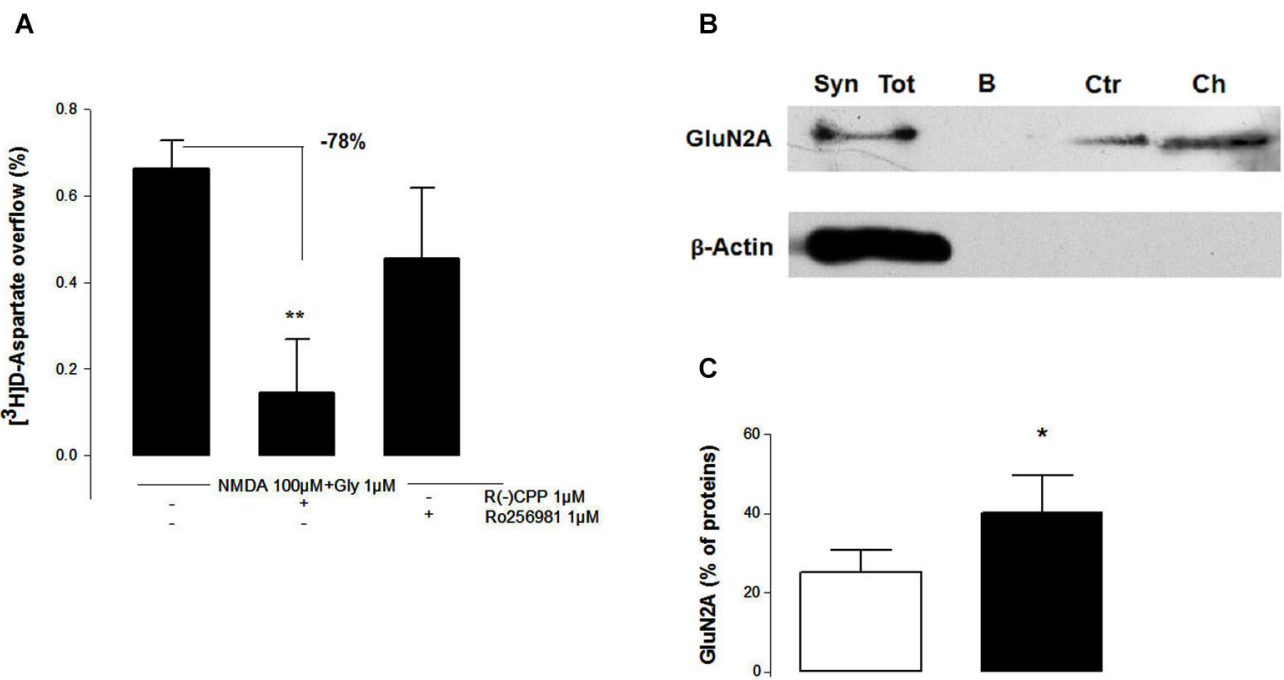

FIGURE 6 | Nicotinic acetylcholine receptors activation selectively bolsters GluN2A-dependent $\left[{ }^{3} \mathrm{H}\right] \mathrm{D}$-Asp release (A) and GluN2A membrane insertion $(B, C)$ in NAc terminals. (A) The selective GluN2A-NMDAR antagonist R(-)CPP, but not the GluN2B-NMDAR antagonist Ro256981, attenuated the potentiating effect resulting from the pre-treatment for $10 \mathrm{~min}$ with $(1 \mathrm{mM}$ Choline) of the evoked $\left[{ }^{3} \mathrm{H}\right] \mathrm{D}$-Asp release from rat NAc synaptosomes triggered by $100 \mu \mathrm{M}$ NMDA and $10 \mu \mathrm{M}$ glycine. Values are mean \pm SEM of six experiments run in triplicate. ${ }^{* *} p<0.01$ vs. control using a one-way ANOVA followed by Tukey-Kramer post hoc test. (B) Representative Western blot of GluN2A subunit surface density in NAc terminals. The Western blots compares total synaptosomal membranes before

adding biotin (Syn Tot), synaptosomal membranes that are not treated with biotin and are subject to a streptavidin pull-down (B), synaptosomal membranes incubated with biotin and subject to a streptavidin pull-down (Ctr) and membranes from synaptosomes that were pre-treated for $1 \mathrm{mM}$ choline before incubation with biotin and pull-down with streptavidin (Ch). The blots are representative of four different experiments carried out with synaptosomal preparations from different rats. (C) Comparison of the average density of biotin-labelled GluN2A proteins in NAc synaptosomal membranes without (open bars) and after (filled bars) a 10 min exposure to 100 $\mu \mathrm{M}$ nicotine. Values are mean \pm SEM of four experiments. ${ }^{*} p<0.05$ using a paired Student's $t$ test. 


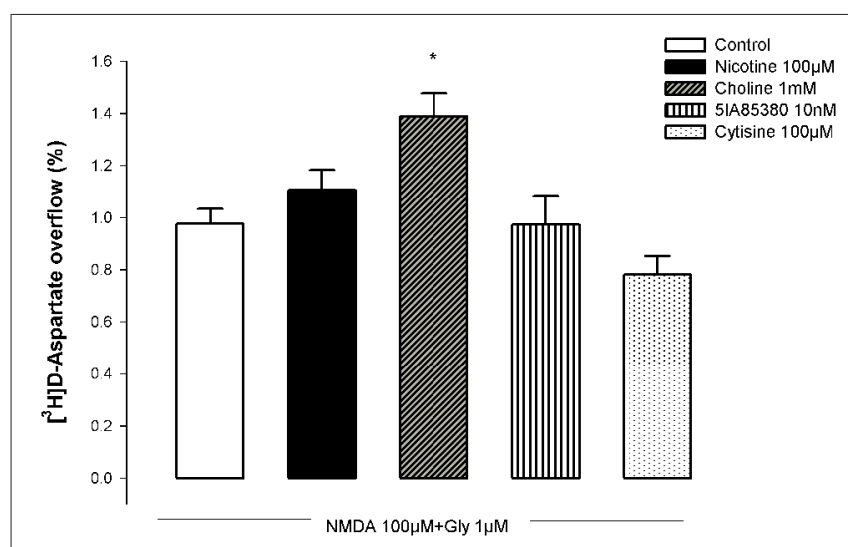

FIGURE 7 | Impact of the pre-treatment with different nAChR agonists on the ability of NMDA to trigger $\left[{ }^{3} \mathrm{H}\right] \mathrm{D}$-Asp outflow from nerve terminals of the rat hippocampus. Each $n A C h R$ agonist was added 10 min before challenging with NMDA. Values are mean \pm SEM of five experiments run in triplicate. ${ }^{*} p<0.05$ vs. control.

GluN2A subunits in NAc terminals, allowing to argue that the nAChR-mediated control of GluN2A trafficking into the plasma membrane underlies the potentiation of presynaptic NMDARmediated actions by nAChR activation in NAc glutamatergic terminals.

Although ionotropic receptors are traditionally recognized as supporting fast synaptic transmission by acting as postsynaptic sensors of released neurotransmitters, evidence accumulated over the last decades also supports a parallel fine-tuning neuromodulation role for ionotropic receptors as controllers of the release of different neurotransmitters (MacDermott et al., 1999; Dorostkar and Boehm, 2008), with critical impact on adaptive changes of synaptic efficiency (Sjöström et al., 2003; Corlew et al., 2008; Bidoret et al., 2009). Accordingly, it has been shown that different $\mathrm{nAChR}$ and NMDAR subtypes are present in glutamatergic nerve terminals in different brain areas, where they efficiently modulate the release of glutamate (McGehee et al., 1995; Marchi et al., 2002; Bardoni et al., 2004; Dickinson et al., 2008; Musante et al., 2011; Gomez-Varela and Berg, 2013). The present study provides an additional layer of complexity in the presynaptic signaling by ionotropic receptors, dwelling on the interaction between presynaptic ionotropic receptors. In fact, building on the observation that different ionotropic receptors are co-localized in nerve terminals, we explored the nature of their interactions to grasp the fine-tuning of neurotransmitter release. Thus, our immunocytochemical findings showed that both $\alpha 7$ and $\alpha 4$ nAChR were co-localized with GluN1 subunits of NMDAR in NAc nerve terminals, namely in glutamatergic nerve endings. This led to the key observation that the two modulation systems are actually engaged in a cross-talk, since the pre-treatment of NAc synaptosomes with nicotine caused a significant increase of the NMDA-evoked intra-terminal cytosolic free calcium transient and $\left[{ }^{3} \mathrm{H}\right] \mathrm{D}$-Asp outflow.

It has been previously described that glutamate exocytosis is controlled by $\alpha 7-\mathrm{nAChR}$ and by $\alpha 4 \beta 2-\mathrm{nAChR}$ subtypes (Dickinson et al., 2008; Zappettini et al., 2010). However, our pharmacological characterization showed a primary involvement of $\alpha 7-n A C h R$ controlling presynaptic NMDA responses, based on the effects of the $\alpha 7-n A C h R$-selective agonist choline and $\alpha 7$-nAChR-selective antagonist $\alpha$-bungarotoxin. This is further confirmed by the lack of effect of 5IA85380, indicating the inability $\alpha 4 \beta 2-n A C h R$ to modify the functional response of presynaptic NMDAR. This contention is further strengthened by our observation that nicotine or choline triggered an increase of the NMDA-induced intra-terminal calcium transients selectively in glutamatergic nerve endings (see Figure 3), which were also endowed with $\alpha 7-n A C h R$. Notably, the impact of nAChR activation was qualitatively similar and displayed a similar pharmacology when measuring the NMDA-induced intra-terminal calcium transients or the release of $\left[{ }^{3} \mathrm{H}\right] \mathrm{D}$-Asp. This strongly suggests that the increased NMDA-evoked outflow of glutamate probably results from the modulation of the calcium transient. Furthermore, it should be noted that $\alpha 4-n A C h R$ are also present in glutamatergic terminals (see Figure 4) and can trigger calcium entry into nerve terminals (Dickinson et al., 2007; Zappettini et al., 2010). However, $\alpha 7$-nAChR triggers a direct calcium entry, whereas the $\alpha 4$-nAChR-mediated increase of intra-terminal free calcium levels involves a depolarization of the terminal and the subsequent activation of voltage-sensitive calcium channels (Dickinson et al., 2007). This prompts the hypothesis that the different mechanisms of nAChR-induced raise of intra-terminal free calcium may be linked to their different ability to control presynaptic NMDAR function, a question that remains to be solved.

The pharmacological characterization of the nAChR-mediated control of presynaptic NMDAR responses also allowed establishing the selective involvement of GluN2A-containing NMDAR, in spite of the known presence of both GluN2A and GluN2B subunits in NMDA autoreceptors located in hippocampal glutamatergic nerve endings (Luccini et al., 2007). In fact, the NMDA-induced outflow of $\left[{ }^{3} \mathrm{H}\right] \mathrm{D}$-Asp was selectively attenuated by selective antagonists of GluN2A-containing NMDAR, whereas selective GluN2B antagonists were devoid of effects. Additionally, the pre-activation of $\mathrm{nAChR}$ selectively bolstered the amplitude of the inhibitory effect of GluN2A antagonists, rather than that of GluN2B antagonists, further indicating the selective nAChR modulation of presynaptic GluN2A-containing NMDAR. This was further re-enforced by the biochemical identification of an increased density of GluN2A subunits in the plasma membrane of NAc terminals after pre-activation of $\mathrm{nAChR}$. This poses the control of the trafficking of NMDAR subunits as the likely mechanism operated by $\mathrm{nAChR}$ to bolster the effects of presynaptic NMDAR, whereas a possible impact on the exocytotic machinery is made unlikely by the lack of effect of $\alpha 7-n A C h R$ activation on the 4APevoked $\left[{ }^{3} \mathrm{H}\right] \mathrm{D}$-Asp outflow. Although the intracellular pathway operated by $\mathrm{nAChR}$ to control GluN2A trafficking remains to be defined, this might involve a nAChR-mediated control of kinase activity, since NMDAR trafficking is regulated by phosphorylation (Lan et al., 2001; Chen and Roche, 2007; Lau and Zukin, 2007).

We have previously reported that $\mathrm{nAChR}$ also controlled NMDAR-mediated responses in NAc dopaminergic terminals, but we found that nAChR activation depressed presynaptic NMDAR-mediated responses (Salamone et al., 2014), in contrast 
to the potentiation observed in NAc glutamatergic terminals and described above. Remarkable, in NAc dopaminergic nerve terminals, we observed that it was the activation of $\alpha 4 \beta 2-n A C h R$ that depressed GluN2B containing NMDAR (Salamone et al., 2014 ), instead of $\alpha 7-n A C h R$ potentiating GluN2A containing NMDAR in NAc glutamatergic terminals. Taken together, these findings indicate a striking difference between the interplay of nAChR and NMDAR in different nerve terminals, which seems to depend on the types of $\mathrm{nAChR}$ and of NMDAR playing the prime role in each different type of nerve terminal within the NAc. This prompted us to test if there were also differences between brain areas and we found that nAChR activation also triggered a potentiation of NMDAR-induced release of $\left[{ }^{3} \mathrm{H}\right] \mathrm{D}$-Asp from hippocampal nerve terminals, as occurred in the NAc glutamatergic terminals. It still remains to understand the signaling mechanisms responsible for the different setup of nAChRs and NMDARs in different types of nerve terminals in the brain.

There is increasing recognition of the importance of presynaptic NMDAR on the control of synaptic plasticity (Sjöström et al., 2003; Corlew et al., 2008; Bidoret et al., 2009), together with the role that adaptive changes in the efficiency of glutamatergic synapses may have in the addictive behavior ( $\mathrm{Ma}$ et al., 2009; Kalivas and Volkow, 2011; Grueter et al., 2012). We characterized the ability of nAChRs to bolster presynaptic NMDAR-mediated responses in NAc glutamatergic terminals. This nAChRs-mediated control of NMDAR function in glutamatergic terminals of the NAc could help to understand the parallel effects of cholinergic and glutamatergic systems on higher brain functions involving information processing in NAc circuits such as mood, memory or addiction (Carlezon and Thomas, 2009; Reissner and Kalivas, 2010).

\section{AUTHOR CONTRIBUTIONS}

Stefania Zappettini, performed calcium imaging analysis, immunocytochemical experiments and release experiments, revised critically the paper and approved the final version; Massimo Grilli contributed to the design of the work, coordinated and performed the release experiments, revised critically the paper and approved the final version, Guendalina Olivero, Jiayang Chen and Cristina Padolecchia performed the release experiments and revised critically the paper and approved the final version; Anna Pittaluga contributed to the design of the work, revised critically the paper and approved the final version; Angelo R. Tomé and Rodrigo A. Cunha contributed to the design of the work and coordinated the calcium imaging analysis and immunocytochemical experiments, revised critically the paper and approved the final version, Mario Marchi provided a substantial contributions to the design of the work and to the interpretation of data and wrote the paper.

\section{ACKNOWLEDGMENTS}

This work was supported by Italian MIUR to Mario Marchi (Prot. $\mathrm{N}^{\circ}$ 2009R7WCZS_003), by University of Genoa "Athenaeum Research Project". We wish to thank Maura Agate and Dr. Silvia E. Smith, Ph.D (University of Idaho, IBEST, School of Life Sciences) for editorial assistance. Rodrigo A. Cunha and Angelo
R. Tomé were supported by QREN (CENTRO-07-ST24-FEDER002006), Fundação para a Ciência e a Tecnologia (PTDC/SAUNSC/122254/2010) and the U.S. Army Research Office and the Defense Advanced Research Projects Agency (grant W911NF-101-0059).

\section{REFERENCES}

Ávila-Ruiz, T., Carranza, V., Gustavo, L. L., Limón, D. I., Martínez, I., Flores, G., et al. (2014). Chronic administration of nicotine enhances NMDA-activated currents in the prefrontal cortex and core part of the nucleus accumbens of rats. Synapse 68, 248-256. doi: 10.1002/syn.21726

Bardoni, R., Torsney, C., Tong, C. K., Prandini, M., and MacDermott, A. B. (2004). Presynaptic NMDA receptors modulate glutamate release from primary sensory neurons in rat spinal cord dorsal horn. J. Neurosci. 24, 2774-2781. doi: 10. 1523/jneurosci.4637-03.2004

Bidoret, C., Ayon, A., Barbour, B., and Casado, M. (2009). Presynaptic NR2Acontaining NMDA receptors implement a high-pass filter synaptic plasticity rule. Proc. Natl. Acad. Sci. U S A 106, 14126-14131. doi: 10.1073/pnas. 0904284106

Callahan, P. M., Terry, A. V. Jr., and Tehim, A. (2014). Effects of the nicotinic $\alpha 7$ receptor partial agonist GTS-21 on NMDA-glutamatergic receptor related deficits in sensorimotor gating and recognition memory in rats. Psychopharmacology (Berl) 231, 3695-3706. doi: 10.1007/s00213-014-3509-2

Carlezon, W. A. Jr., and Thomas, M. J. (2009). Biological substrates of reward and aversion: a nucleus accumbens activity hypothesis. Neuropharmacology 56(Suppl 1), 122-132. doi: 10.1016/j.neuropharm.2008.06.075

Castro, E., Mateo, J., Tomé, A. R., Barbosa, R. M., Miras-Portugal, M. T., and Rosário, L. M. (1995). Cell-specific purinergic receptors coupled to $\mathrm{Ca}^{2+}$ entry and $\mathrm{Ca}^{2+}$ release from internal stores in adrenal chromaffin cells. Differential sensitivity to UTP and suramin. J. Biol. Chem. 270, 5098-5106. doi: 10.1074/jbc. 270.10 .5098

Chen, B. S., and Roche, K. W. (2007). Regulation of NMDA receptors by phosphorylation. Neuropharmacology 53, 362-368. doi: 10.1016/j.neuropharm.2007. 05.018

Ciruela, F., Casadó, V., Rodrigues, R. J., Luján, R., Burgueño, J., Canals, M., et al. (2006). Presynaptic control of striatal glutamatergic neurotransmission by adenosine $\mathrm{A}^{1}-\mathrm{A}^{2 A}$ receptor heteromers. J. Neurosci. 26, 2080-2087. doi: 10. 1523/jneurosci.3574-05.2006

Corlew, R., Brasier, D. J., Feldman, D. E., and Philpot, B. D. (2008). Presynaptic NMDA receptors: newly appreciated roles in cortical synaptic function and plasticity. Neuroscientist 14, 609-625. doi: 10.1177/1073858408322675

Delibas, N., Doguc, D. K., Sutcu, R., Eroglu, E., and Gökalp, O. (2005). Effect of nicotine on hippocampal nicotinic acetylcholine alpha7 receptor and NMDA receptor subunits $2 \mathrm{~A}$ and $2 \mathrm{~B}$ expression in young and old rats. Int. J. Neurosci. 115, 1151-1163. doi: 10.1080/00207450590914437

Dickinson, J. A., Hanrott, K. E., Mok, M. H., Kew, J. N., and Wonnacott, S. (2007). Differential coupling of alpha7 and non-alpha7 nicotinic acetylcholine receptors to calcium-induced calcium release and voltage-operated calcium channels in PC12 cells. J. Neurochem. 100, 1089-1096. doi: 10.1111/j.1471-4159.2006. 04273.x

Dickinson, J. A., Kew, J. N., and Wonnacott, S. (2008). Presynaptic alpha 7and beta 2-containing nicotinic acetylcholine receptors modulate excitatory amino acid release from rat prefrontal cortex nerve terminals via distinct cellular mechanisms. Mol. Pharmacol. 74, 348-359. doi: 10.1124/mol.108.04 6623

Dorostkar, M. M., and Boehm, S. (2008). Presynaptic ionotropic receptors. Handb. Exp. Pharmacol. 184, 479-527. doi: 10.1007/978-3-540-74805-2_15

Giocomo, L. M., and Hasselmo, M. E. (2007). Neuromodulation by glutamate and acetylcholine can change circuit dynamics by regulating the relative influence of afferent input and excitatory feedback. Mol. Neurobiol. 36, 184-200. doi: 10. 1007/s12035-007-0032-z

Gomez-Varela, D., and Berg, D. K. (2013). Lateral mobility of presynaptic $\alpha 7$ containing nicotinic receptors and its relevance for glutamate release. J. Neurosci. 33, 17062-17071. doi: 10.1523/jneurosci.1482-13.2013

Grilli, M., Patti, L., Robino, F., Zappettini, S., Raiteri, M., and Marchi, M. (2008). Release-enhancing pre-synaptic muscarinic and nicotinic receptors co-exist and interact on dopaminergic nerve endings of rat nucleus accumbens. $J$. Neurochem. 105, 2205-2213. doi: 10.1111/j.1471-4159.2008.05307.x 
Grilli, M., Summa, M., Salamone, A., Olivero, G., Zappettini, S., Di Prisco, S., et al. (2012). In vitro exposure to nicotine induces endocytosis of presynaptic AMPA receptors modulating dopamine release in rat nucleus accumbens nerve terminals. Neuropharmacology 63, 916-926. doi: 10.1016/j.neuropharm.2012. 06.049

Grilli, M., Zappettini, S., Raiteri, L., and Marchi, M. (2009). Nicotinic and muscarinic cholinergic receptors coexist on GABAergic nerve endings in the mouse striatum and interact in modulating GABA release. Neuropharmacology 56, 610 614. doi: 10.1016/j.neuropharm.2008.10.014

Grueter, B. A., Rothwell, P. E., and Malenka, R. C. (2012). Integrating synaptic plasticity and striatal circuit function in addiction. Curr. Opin. Neurobiol. 22, 545-551. doi: 10.1016/j.conb.2011.09.009

Kalivas, P. W., and Volkow, N. D. (2011). New medications for drug addiction hiding in glutamatergic neuroplasticity. Mol. Psychiatry 16, 974-986. doi: 10. 1038/mp.2011.46

Lan, J. Y., Skeberdis, V. A., Jover, T., Grooms, S. Y., Lin, Y., Araneda, R. C., et al. (2001). Protein kinase C modulates NMDA receptor trafficking and gating. Nat. Neurosci. 4, 382-390. doi: 10.1038/86028

Lau, C. G., and Zukin, R. S. (2007). NMDA receptor trafficking in synaptic plasticity and neuropsychiatric disorders. Nat. Rev. Neurosci. 8, 413-426. doi: 10. $1038 /$ nrn 2171

Levin, E. D., Tizabi, Y., Rezvani, A. H., Caldwell, D. P., Petro, A., and Getachew, B. (2005). Chronic nicotine and dizocilpine effects on regionally specific nicotinic and NMDA glutamate receptor binding. Brain Res. 1041, 132-142. doi: 10. 1016/j.brainres.2005.01.104

Lev-Ram, V., Miyakawa, H., Lasser-Ross, N., and Ross, W. N. (1992). Calcium transients in cerebellar Purkinje neurons evoked by intracellular stimulation. J. Neurophysiol. 68, 1167-1177.

Li, S., Nai, Q., Lipina, T. V., Roder, J. C., and Liu, F. (2013). $\alpha 7$ nAchR/NMDAR coupling affects NMDAR function and object recognition. Mol. Brain 6:58. doi: 10.1186/1756-6606-6-58

Liechti, M. E., and Markou, A. (2008). Role of the glutamatergic system in nicotine dependence: implications for the discovery and development of new pharmacological smoking cessation therapies. CNS Drugs 22, 705-724. doi: 10 . 2165/00023210-200822090-00001

Lin, H., Vicini, S., Hsu, F. C., Doshi, S., Takano, H., Coulter, D. A., et al. (2010). Axonal $\alpha 7$ nicotinic ACh receptors modulate presynaptic NMDA receptor expression and structural plasticity of glutamatergic presynaptic boutons. Proc. Natl. Acad. Sci. US A 107, 16661-16666. doi: 10.1073/pnas.1007397107

Luccini, E., Musante, V., Neri, E., Raiteri, M., and Pittaluga, A. (2007). N-methyl$\mathrm{D}$-aspartate autoreceptors respond to low and high agonist concentrations by facilitating, respectively, exocytosis and carrier-mediated release of glutamate in rat hippocampus. J. Neurosci. Res. 85, 3657-3665. doi: 10.1002/jnr.21446

Ma, Y. Y., Cepeda, C., and Cui, C. L. (2009). The role of striatal NMDA receptors in drug addiction. Int. Rev. Neurobiol. 89, 131-146. doi: 10.1016/s00747742(09)89006-5

MacDermott, A. B., Role, L. W., and Siegelbaum, S. A. (1999). Presynaptic ionotropic receptors and the control of transmitter release. Annu. Rev. Neurosci. 22, 443-485. doi: 10.1146/annurev.neuro.22.1.443

Marchi, M., Risso, F., Viola, C., Cavazzani, P., and Raiteri, M. (2002). Direct evidence that release-stimulating alpha ${ }^{\star}$ nicotinic cholinergic receptors are localized on human and rat brain glutamatergic axon terminals. J. Neurochem. 80, 1071-1078. doi: 10.1046/j.0022-3042.2002.00805.x

McGehee, D. S., Heath, M. J., Gelber, S., Devay, P., and Role, L. W. (1995). Nicotine enhancement of fast excitatory synaptic transmission in CNS by presynaptic receptors. Science 269, 1692-1696. doi: 10.1126/science.7569895
Musante, V., Summa, M., Cunha, R. A., Raiteri, M., and Pittaluga, A. (2011). Presynaptic glycine GlyT1 transporter-NMDA receptor interaction: relevance to NMDA autoreceptor activation in the presence of $\mathrm{Mg}^{2+}$ ions. J. Neurochem. 117, 516-527. doi: 10.1111/j.1471-4159.2011.07223.x

Paxinos, G., and Watson, C. (1986). The Rat Brain in Stereotaxic Coordinates. 2nd Edn. San Diego, CA, USA: Academic Press.

Reissner, K. J., and Kalivas, P. W. (2010). Using glutamate homeostasis as a target for treating addictive disorders. Behav. Pharmacol. 21, 514-522. doi: 10.1097/fbp. 0b013e32833d41b2

Rodrigues, R. J., Almeida, T., Richardson, P. J., Oliveira, C. R., and Cunha, R. A. (2005). Dual presynaptic control by ATP of glutamate release via facilitatory $\mathrm{P} 2 \mathrm{X} 1, \mathrm{P} 2 \mathrm{X} 2 / 3$ and $\mathrm{P} 2 \mathrm{X} 3$ and inhibitory P2Y1, P2Y2 and/or P2Y4 receptors in the rat hippocampus. J. Neurosci. 25, 6286-6295. doi: 10.1523/jneurosci.062805.2005

Salamone, A., Zappettini, S., Grilli, M., Olivero, G., Agostinho, P., Tomé, A. R., et al. (2014). Prolonged nicotine exposure down-regulates presynaptic NMDA receptors in dopaminergic terminals of the rat nucleus accumbens. Neuropharmacology 79, 488-497. doi: 10.1016/j.neuropharm.2013.12.014

Sjöström, P. J., Turrigiano, G. G., and Nelson, S. B. (2003). Neocortical LTD via coincident activation of presynaptic NMDA and cannabinoid receptors. Neuron 39, 641-654. doi: 10.1016/s0896-6273(03)00476-8

Timofeeva, O. A., and Levin, E. D. (2011). Glutamate and nicotinic receptor interactions in working memory: importance for the cognitive impairment of schizophrenia. Neuroscience 195, 21-36. doi: 10.1016/j.neuroscience.2011. 08.038

Wang, F., Chen, H., Steketee, J. D., and Sharp, B. M. (2007). Upregulation of ionotropic glutamate receptor subunits within specific mesocorticolimbic regions during chronic nicotine self-administration. Neuropsychopharmacology 32, 103-109. doi: 10.1038/sj.npp.1301033

Yamazaki, Y., Jia, Y., Niu, R., and Sumikawa, K. (2006). Nicotine exposure in vivo induces long-lasting enhancement of NMDA receptor-mediated currents in the hippocampus. Eur. J. Neurosci. 23, 1819-1828. doi: 10.1111/j.1460-9568.2006. 04714.x

Zappettini, S., Grilli, M., Salamone, A., Fedele, E., and Marchi, M. (2010). Presynaptic nicotinic receptors evoke endogenous glutamate and aspartate release from hippocampal synaptosomes by way of distinct coupling mechanisms. Br. J. Pharmacol 161, 1161-1171. doi: 10.1111/j.1476-5381.2010.00958.x

Conflict of Interest Statement: The authors declare that the research was conducted in the absence of any commercial or financial relationships that could be construed as a potential conflict of interest.

Received: 24 July 2014; accepted: 30 September 2014; published online: 16 October 2014.

Citation: Zappettini S, Grilli M, Olivero G, Chen J, Padolecchia C, Pittaluga A, Tomé $A R$, Cunha RA and Marchi $M$ (2014) Nicotinic $\alpha 7$ receptor activation selectively potentiates the function of NMDA receptors in glutamatergic terminals of the nucleus accumbens. Front. Cell. Neurosci. 8:332. doi: 10.3389/fncel.2014.00332

This article was submitted to the journal Frontiers in Cellular Neuroscience.

Copyright (c) 2014 Zappettini, Grilli, Olivero, Chen, Padolecchia, Pittaluga, Tomé, Cunha and Marchi. This is an open-access article distributed under the terms of the Creative Commons Attribution License (CC BY). The use, distribution and reproduction in other forums is permitted, provided the original author(s) or licensor are credited and that the original publication in this journal is cited, in accordance with accepted academic practice. No use, distribution or reproduction is permitted which does not comply with these terms. 